SCARr, M. P. (1951). J. gen. Microbiol. 5, 704-713.

\title{
Osmophilic Yeasts in Raw Beet and Cane Sugars and Intermediate Sugar-Refining Products
}

\author{
By M. PAMELA SCARR \\ Tate \& Lyle, Ltd., Ravensbourne, Westerham Road, Keston, Kent
}

\begin{abstract}
SUMMARY: Osmophilic yeasts are found in the film of molasses on the crystals of raw sugars and in intermediate sugar-refining products of a wide range of concentration. They are allied to yeasts found in similar situations such as concentrated fruit juices, etc., and can be made to spore more or less freely under dry conditions, usually with conjugation. They are unable to destroy sucrose in strongly buffered solutions; some are able to produce sufficient acid from traces of invert sugar present gradually to invert the sucrose. During this process multiplication takes place. Previous workers have shown that the majority of organisms of this group is highly acid resistant.

Organisms which grow in a wide range of concentration of dissolved solids (salts, sugar) show, at acid $\mathrm{pH}$ values, an adaptation to growth in higher concentrations accompanied by a diminished metabolic rate. This is lost after a period of 6-8 weeks in dilute media, but can be revived in many cases by increasing the sugar concentration in not less than two steps. Temperature resistance is also increased in concentrated media.
\end{abstract}

According to Henrici's monograph (1941) the term osmophilic was first applied by Richter in 1912 to micro-organisms which multiply in solutions of high osmotic pressure. Apart from the brine yeasts, this term is most frequently applied to the yeasts tolerant of high sugar concentration to be found in a wide range of natural and manufactured products. Nussbaumer (1910) was the first to find that osmophilic yeasts were a factor in honey spoilage, and Lochhead \& Heron (1929) traced these to the honey of various flowers. Kroemer \& Krumbholtz (1931) studied similar organisms in fermenting wine musts produced from grapes infected with Botrytis cinerea; Baker \& Mrak (1938) found organisms from the same group on crystallized fruit; Sacchetti $(1932,1939)$ studied the microflora of fruit juices, Italian wine musts and honey; Owen (1948) has reported the presence of Torulopsis spp. in sugars and molasses.

More detailed diagnostic work on honey by Lochhead \& Farrell (1931) and Lochhead \& McMasters (1931), on honey and wine musts by Sacchetti (1932, 1939), and on fruit juices by Ingram $(1949 a, b)$ showed that the majority of organisms involved belonged to the sub-genus Zygosaccharomyces Barker and many were osmophilic strains of known species. Kroemer \& Krumbholtz (1931) divide the osmophilic zygosaccharomyces on physiological grounds into two groups :

(1) Those which will only grow in solutions of high concentration are able to ferment disaccharides and produce little volatile acid. 
(2) Those which will grow in solutions of a wide range of concentration, so that they tolerate rather than require concentrated solutions; they ferment much less vigorously than Group 1, and produce varying quantities of volatile acid.

The present investigation was concerned with the isolation of osmophilic yeasts from raw sugar and intermediate refinery products, with a view to physiological and ecological study.

\section{PRELIMINARY STUDY}

Yeasts in sugar can be traced back to the original cane (Pl. 1, figs. I and 2); in raw sugar they are found in the film of molasses round each crystal, and when crystals are mounted in a little water, these yeasts can be seen under the microscope streaming away from the surface of the crystal as the molasses mix with the surrounding medium. Hyphae of the Aspergillus glaucus group of moulds are occasionally found there (Pl. 1, fig. 3), but the yeasts are far more common, and, in a water-damaged sugar, may be as high as 5 million/g. sugar (de Whalley \& Scarr, 1947).

So far, forty strains of yeast have been isolated from raw cane sugars from the West Indies, Africa and Australia, as well as from a few samples of beet grown in Gt. Britain, and from intermediate refinery products. Most of these yeasts form asci under standard conditions (Phaff \& Mrak, 1948, 1949) provided the medium be dry, although usually only sparsely (Pl. 1, fig. 4). Asci are formed with or without previous anisogamous conjugation, and 1 to 4 (usually 2) ascospores are produced. A sediment is produced in wort and in some cases also a surface ring. Pseudomycelium when formed is normally in the sediment, so that lack of oxygen may stimulate this formation (Pl. 1, fig. 5).

All forty yeasts appear to belong to Kroemer \& Krumbholtz's second group, as they are tolerant of a wide range of sugar concentrations similar to those found in fruit juices (Ingram, $1949 a, b$ ). Similarly, these yeasts gradually lose this property when kept in dilute solutions for 6 to 8 weeks. It may, however, be quickly regained by increasing the concentration in at least two steps. In spite of the large excess of sucrose present, under natural conditions, they show the property of this group that they are unable to ferment sucrose, confirming earlier reports from Browne (1908) on the microflora of sugars. However, previous observations in these laboratories on the destruction of sugar in unsterilized refinery syrups showed large numbers of these organisms which multiplied slowly, even in the refrigerator. Therefore one of the most active yeasts was grown in a medium containing $40 \%$ sucrose in aerated culture, and then centrifuged and allowed to autolyse under toluene. Neither the yeast nor the autolysate caused any inversion when left with a fresh $5 \%$ sucrose solution overnight at room temperature, so that it was concluded that the yeast contained negligible quantities of sucrase (Kluyver \& Custers, 1940). The standard plate auxanogram described by Wickerham \& Burton (1948) similarly gave no results, but with their liquid auxanogram, some 
yeasts did show positive results after 2 to 3 weeks, provided yeast extract were present, thus indicating that sucrose destruction does take place, either through an adaptive enzyme or by some other means.

The main part of this work was planned on the above findings to show what the nature of high sugar-tolerance might be, and how sucrose destruction might take place.

\section{METHODS}

The greater part of the work was carried out with a strain of Zygosaccharomyces sp., strain 21, isolated from a Cuban raw sugar; this was a single-cell isolate, selected because it gave a positive auxanogram for sucrose. For comparative purposes, strain 32, a single-cell isolate from a Natal raw sugar, which gave a negative auxanogram with sucrose, and a culture of Saccharomyces carlsbergensis Hansen from the Centraal Bureau voor Schimmelcultures, Delft, Holland, were used. The osmophilic yeasts were stored on a special medium used in these laboratories (de Whalley \& Scarr, 1947) consisting of an artificial wort agar made up in a $45 \%$ solids syrup containing glucose and sucrose. The $S$. carlsbergensis was stored on Difco wort agar.

The osmophilic yeasts were 72 -hr. cultures, and the other yeasts $48-\mathrm{hr}$. cultures, because of their faster rate of multiplication. The yeast extract used was Yeastrel (Brewers' Food Supply Co. Ltd.). Cultures for inoculation were suspended in a small portion of the reaction medium immediately before use. Citric acid-disodium phosphate buffer (McIlvaine; see Britton, 1944) was used throughout as the yeasts gave a negative auxanogram with citric acid and appeared unaffected by excess phosphate. All experiments were made in unaerated solutions unless otherwise stated, using $20 \mathrm{ml}$. of medium in 6 in. $\times 1$ in. test-tubes.

All sugar solutions were sterilized by filtration. The following media were used: (1) for dilute solutions in the physical investigations: sucrose $5 \%$; glucose $1 \%$; Evans Bact. Peptone 0.5\%; $\mathrm{KH}_{2} \mathrm{PO}_{4}$ (Analar) $0.1 \% ; \mathrm{MgSO}_{4}$ (Analar) trace; $\mathrm{FeSO}_{4}$ (Analar) trace; (2) for the concentrated solutions: $54 \% \mathrm{w} / \mathrm{w}$ of sucrose instead of $5 \%$; (3) for the nutritional investigations: sucrose $50 \% \mathrm{w} / \mathrm{w}$; glucose $1 \% \mathrm{w} / \mathrm{w} ; \mathrm{KH}_{2} \mathrm{PO}_{4}$ (Analar) $0.1 \% ;\left(\mathrm{NH}_{4}\right)_{2} \mathrm{SO}_{4}$ (Analar) $0.5 \% ; \mathrm{MgSO}_{4}$ (Analar) trace; $\mathrm{FeSO}_{4}$ (Analar) trace.

\section{RESULTS}

\section{Visual observations}

Old cultures had a strong surface ring in concentrated media with both osmophilic yeasts, but only strain 21 formed one in dilute media. With both strains under anaerobic conditions in concentrated solution the yeasts grew in clumps which appeared in nigrosine to have capsules; these might have been merely layers of concentrated syrup, as they gradually diffused into the surrounding medium. In aerated solutions, cells of strain 21 were seen singly or in pairs, and the apparent capsule was still present.

On transference to high concentrations of sucrose, 50-90\% of the yeast cells assumed a transient shrunken condition with dense cell contents and 
became half their normal size. This appeared to be some form of plasmolysis, as the cells recovered under conditions where multiplication could take place. Normal plasmolysis was seen occasionally. There was little change in the size of actively growing cells at different concentrations, although they were slightly smaller in the stronger solution.

The relationship between temperature and the concentration of solids in the medium

Media 1 and 2 were buffered with $0 \cdot 1 \mathrm{M}$ citric acid and $0 \cdot 2 \mathrm{M}$ sodium phosphate to $\mathrm{pH} 4 \cdot 5$, inoculated with suspensions of cultures of strain 21 , strain 32 or $S$. carlsbergensis, and incubated at $25^{\circ}, 35^{\circ}$, and $41^{\circ}$, and, for the higher concentration of sucrose, at $50^{\circ}$. Growth at $4^{\circ}$ was omitted as being too slow.

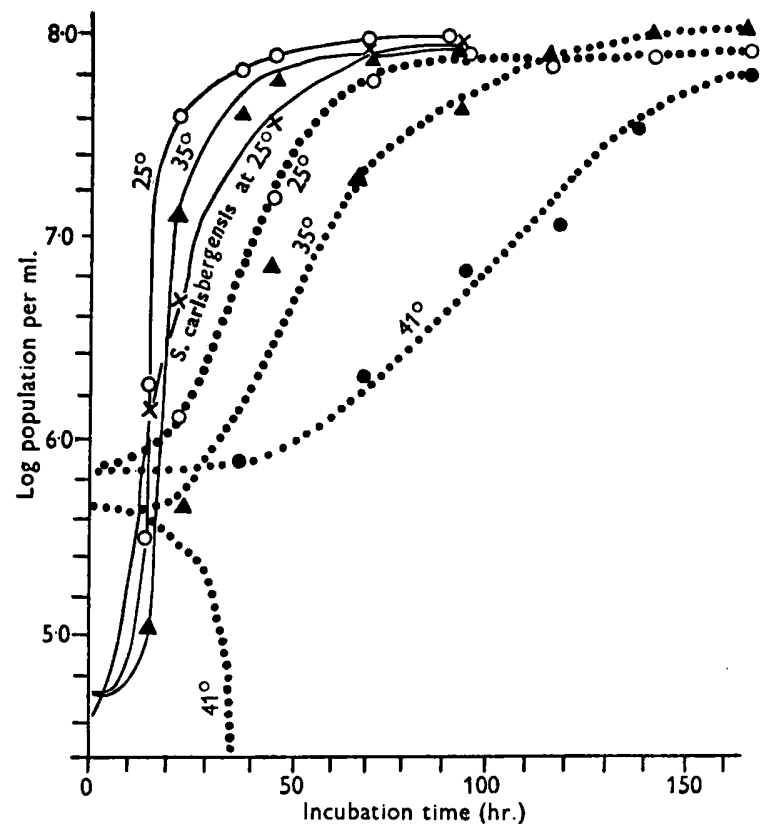

Fig. 1. Variation in growth of strain 21. Zygosaccharomyces sp. with concentration and temperature. ....., growth in solutions containing $54 \% \mathrm{w} / \mathrm{w}$ sucrose; —, growth in solutions containing $5 \% \mathrm{w} / \mathrm{w}$ sucrose.

Growth was followed by haemacytometer counts (Fig. 1). The effect of increased concentration is in each case to decrease the multiplication rate, and to raise the optimum temperature from $25^{\circ}$ to $35^{\circ}$.

These results are quite consistent if it be assumed that the cells adopt a latent state somewhere between that of actively dividing cells and such a latent form as a bacterial spore. As absorption both of water (Bennet-Clarke, 1948) and nutrients (Hoagland, 1944) depends directly on metabolic activity in all plant cells, it is reasonable to suppose that, as metabolism continues at a much slower rate under physiologically drier conditions autolysis is delayed 
and the transient shrunken condition of the cells is overcome. If this is so, it explains why the optimum temperature is higher under conditions of higher concentration; on the other hand, it is surprising that the decrease in multiplication rate is not even greater.

The relationship between $p H$ value and the concentration of solids in the medium

Media 1 and 2 were buffered with $0.1 \mathrm{M}$ citric acid and $0.2 \mathrm{M}$ sodium phosphate to $\mathrm{pH}$ values between $2 \cdot 5$ and $7 \cdot 5$ and inoculated with strain 21 . All cultures were incubated at $\mathbf{2 5}^{\circ}$. Growth was followed by haemacytometer counts (Fig. 2).

It appears that for strain 21 the $\mathrm{pH}$ value is a controlling factor in the adaptation to growth in solutions containing higher concentrations of sucrose. These results also demonstrate the acid-resistance of the yeast used and its similarity to other yeasts (Nickerson, 1943) of this group.

\section{Nutritional requirements}

Medium 3 was used in ten media made up as follows:

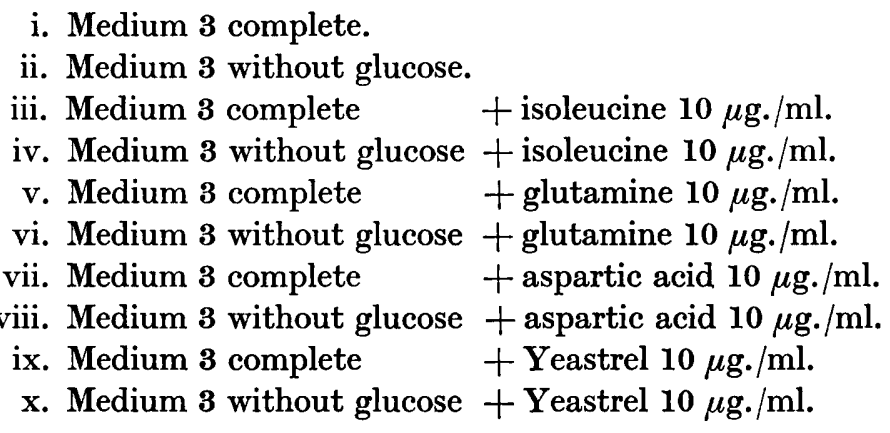

The media were inoculated with a suspension of strain 21, and duplicates of media $i, i i$, ix and $x$ were inoculated with a suspension of strain 32 . Growth was followed as before. All solutions were buffered to $\mathrm{pH} \mathrm{4.5}$ with $0.01 \mathrm{M}$ sodium phosphate and $0.01 \mathrm{~m}$ citric acid and incubated at $25^{\circ}$.

Tubes of media i, ii, ix and $x$ were first inoculated with strain 21 or strain 32 (Fig. 3). There was a long lag period before multiplication began in the medium lacking glucose, and during that period, $99 \%$ of the cells were in the shrunken condition. The effect of adding yeast extract to the medium not containing glucose was at first sight peculiar with strain 21. Some residual nutrients were introduced with the inoculum, which caused slight multiplication of the more active yeast. During the ensuing stationary phase, the pH values dropped from $4 \cdot 6$ to 3 and multiplication began again. Equivalent amounts of amino-acids produced the same effect with strain 21, as shown in Fig. 4.

Cultures left for more than ten days continued to multiply at a much slower rate. Counts after three weeks of cultures of strain 21 containing no 


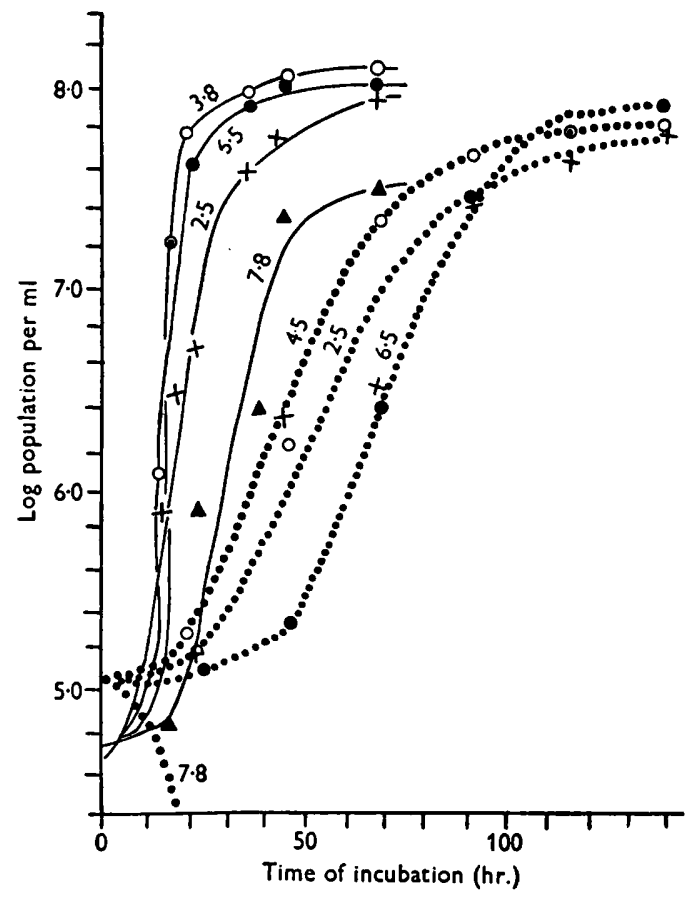

Fig. 2. Variation in growth of strain 21. Zygosaccharomyces sp. with concentration and pH. .........., growth in solution containing $54 \% \mathrm{w} / \mathrm{w}$ sucrose; — containing $5 \% \mathrm{w} / \mathrm{w}$ sucrose.

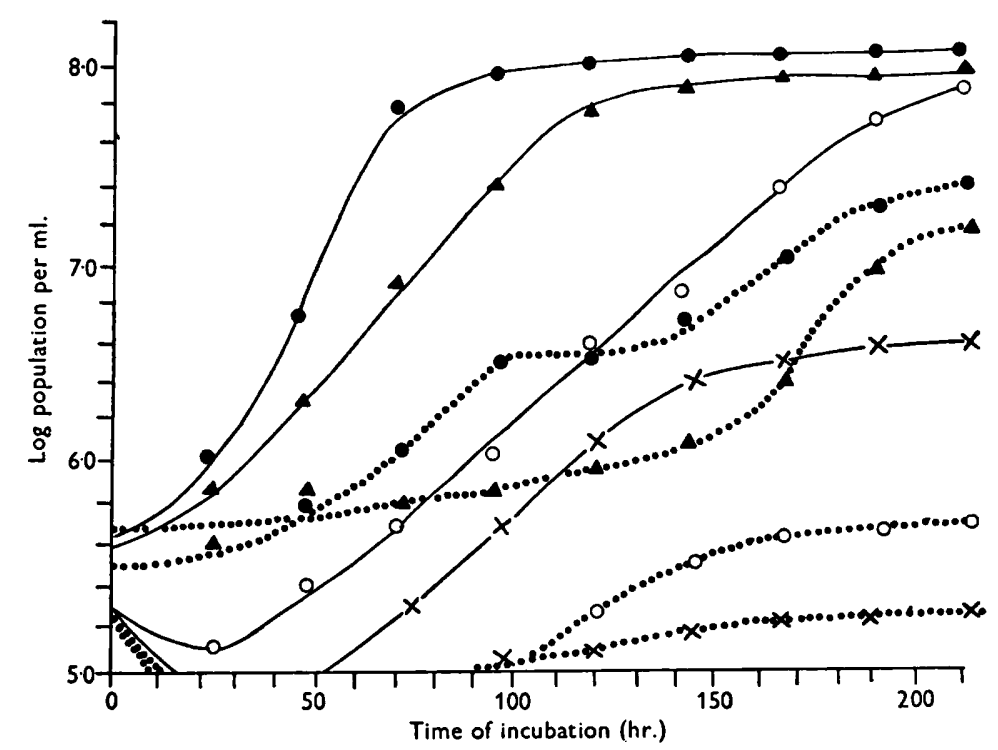

Fig. 3. Effect of Glucose (1\%) and Yeastrel $(10 \mu \mathrm{g}$. $/ \mathrm{ml}$.) on growth of strains 21 and 32. Zygosaccharomyces spp. - medium containing $50 \% \mathrm{w} / \mathrm{w}$ sucrose and $1 \% \mathrm{w} / \mathrm{w}$ glucose; ................, medium containing $50 \% \mathrm{w} / \mathrm{w}$ sucrose but no glucose; g- - , strain 21 with $10 \mu \mathrm{g}$. added Yeastrel/ml.; $-\mathbf{\Delta}-\mathbf{\Delta}-$, strain 21 without $10 \mu \mathrm{g}$. added Yeastrel/ml.; $-\mathrm{O}-\mathrm{O}-$, strain 32 with $10 \mu \mathrm{g}$. added Yeastrel $/ \mathrm{ml} . ;-x-x-$, strain 32 without added Yeastrel. 
original glucose were: Blank, complete medium without glucose $=9,800 \times 10^{4}$ cells $/ \mathrm{ml}$.; the same, plus yeast extract $=20,500 \times 10^{4}$ cells $/ \mathrm{ml}$.; the same, plus isoleucine $=19,600 \times 10^{4}$ cells $/ \mathrm{ml}$.

In every case, the final $\mathrm{pH}$ value for strain 21 was approximately $2 \cdot 8$, and for strain 32, 3.2 after nine days. There was little further drop at the end of three weeks when the $\mathrm{pH}$ was approximately $2 \cdot 4$. In order to trace this fall in $\mathrm{pH}$ in more detail, the complete medium was made up buffered with $0.01 \mathrm{~m}$ citric acid and $0.02 \mathrm{M}$ sodium phosphate to $\mathrm{pH} 4 \cdot 7$, and containing a small quantity of initial dextrose to accelerate the reaction; $400 \mathrm{ml}$. were incubated at room temperature, subjected to gentle aeration (by a 1/150 h.p. rotary pump (Charles Austin \& Co.) mainly to keep the solution stirred and to avoid the accumulation of any carbon dioxide. The culture was examined at intervals for cell content, $\mathrm{pH}$ (glass electrode), refractrometric solids, and at the start and finish for invert by the methylene blue method (de Whalley, 1937) (Fig. 5).

Here there was sufficient acid formed by the small amount of dextrose present at the beginning of the experiment to start the accumulative reaction which by the end of the week had inverted nearly half of the sucrose, the invert content increasing from $1 \cdot 14$ to $21 \% \mathrm{w} / \mathrm{w}$ on sample. At the same time the concentration had dropped from $49.5 \%$ to $46 \% \mathrm{w} / \mathrm{w}$ solids. As in raw sugar there is normally much less initial invert, the above reaction would take longer to reach completion. This also presumably happened with the second strain of yeast, which produced less acid and, therefore, less inversion. Quantitative or qualitative estimations of the acids formed have not yet been attempted.

\section{CONCLUSION}

Most of the organisms found growing in the film of molasses on sugar crystals belonged to the same sub-genus as osmophilic yeasts from similar sources. Those met with so far were not strict osmophiles but were tolerant of high concentrations of sugar. They also produced considerable quantities of acid, and were weakly fermentative.

It was not found possible to extract invertase from the yeasts chiefly examined, yet it was evident that sucrose was destroyed under natural conditions. The large amount of acid gradually produced explains this, as in weakly buffered solutions, the $\mathrm{pH}$ value steadily dropped, and during this process inversion by acid gradually took place. The second yeast, which appeared to produce less acid, showed less reaction. The thick surface ring produced in old cultures in concentrated syrups indicated that the process was mainly aerobic.

Comparing the growth reactions in $5 \%$ and $54 \%$ sucrose solutions, it was found that the optimum temperature was higher, the $\mathrm{pH}$ was lower, and the multiplication rate was much slower at the higher concentrations. Outside these ranges, a preliminary shrinkage of the whole cell, which always occurred after inoculation, was not overcome and the cells were apparently moribund. 


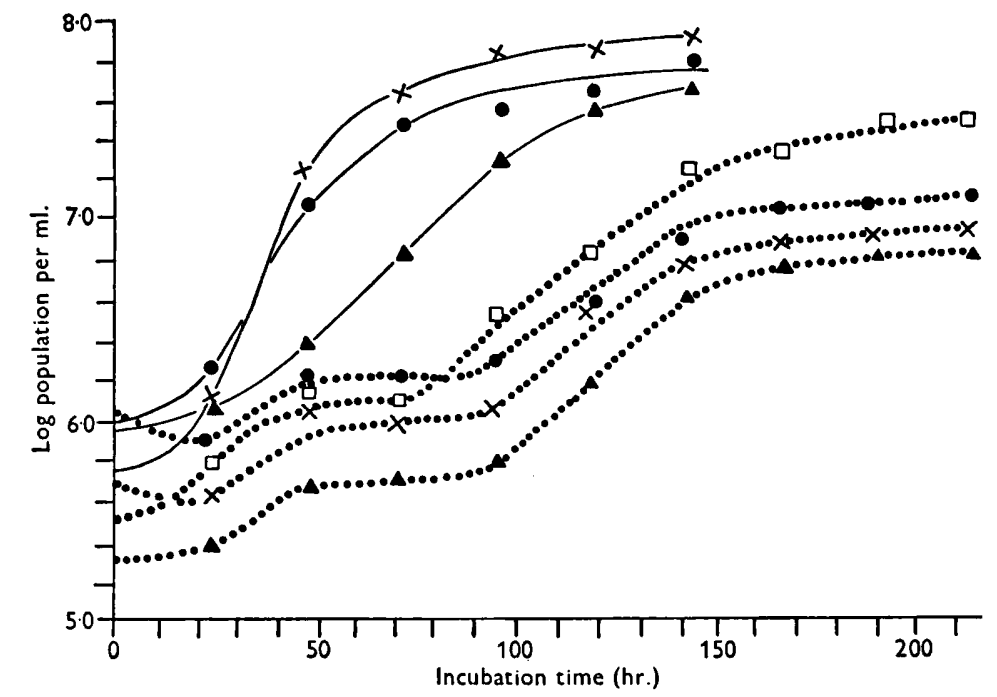

Fig. 4. Effect of amino-acids on growth rates of strain 21. Zygosaccharomyces sp. (40 $\mu \mathrm{g}$. amino-acid per ml.) growing in $50 \% \mathrm{w} / \mathrm{w}$ sucrose solutions. - - with $1 \% \mathrm{w} / \mathrm{w}$ added glucose; .........., without $1 \% \mathrm{w} / \mathrm{w}$ added glucose; $-\times-\times-$, with added glutamine; - $-\bullet-$, with added isoleucine; $-\mathbf{\Delta}-\mathbf{\Delta}-$, with added aspartic acid; $-\square-\square-$, with added Yeastrel.

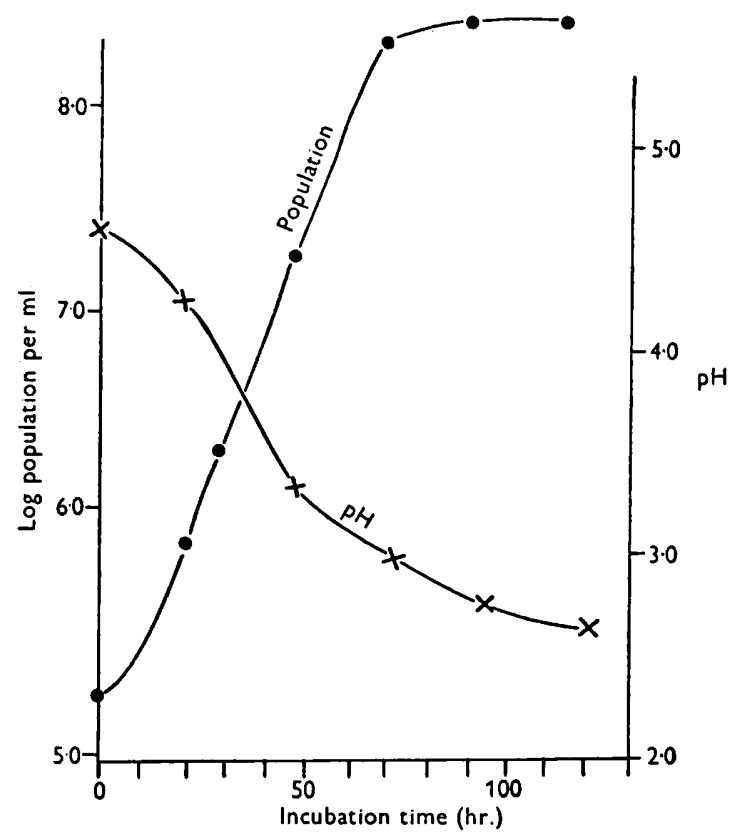

Fig. 5. Acid formation in complete medium containing dextrose (1\%) and sucrose $(50 \%)$ under gentle aeration. $-\times-\times-, \mathrm{pH}$ change per unit time; - population change per unit time. 
The author wishes to thank Tate \& Lyle Ltd. for permission to publish this paper; Mr H. C. S. de Whalley, the Director of Research of Tate \& Lyle Ltd., and Dr M. Ingram of the Low Temperature Research Station, Cambridge, for their continued advice and encouragement; $\mathrm{Dr} H$. M. Thompson for checking some of the figures and Mr F. Carman for producing the photographs.

\section{REFERENCES}

Baker, E. E. \& Mrak, E. M. (1938). Yeasts associated with the 'sugaring' of dried prunes and figs. J. Bact. 36, 316.

Bennet-Clarke, T. A. (1948). Non-osmotic movement in plant cells. Faraday Soc. Discussion, 3, 134.

Britron, H. T. (1944). Hydrogen Ions. Vol. 1. London: Chapman \& Hall.

Browne, C. A. (1908). Handbook of Sugar Analysis, 1st ed. New York: Wiley \& Sons.

Henricr, A. T. (1941). The Yeasts: Genetics, cytology, variation, classification and identification. Bact. Rev. 5, 97.

Hoagland, D. R. (1944). Inorganic Nutrition. Waltham, Mass., U.S.A.: Chronica Botanica Co.

INGRAM, M. (1949a). Fermentation in concentrated orange juice. Part I. Food Manuf. 24, 77.

Ingram, M. $(1949 b)$. Fermentation in concentrated orange juice. Part II. Food Manuf. 24, 121.

KLuYver, A. J. \& Custers, M. T. J. (1940). Suitability of disaccharides as respiration and assimilation substrates for yeasts which do not ferment sugars. Antonie van Leeurvenhoek J. Microbiol. Serol. 6, 121.

Kroemer, K. \& Krumbholtz, G. (1931). Untersuchungen über osmophile Sprosspilze. I. Beiträge zur Kenntnis der Gärungsvorgänge und der Gärungserreger der Trockenbeerenauslesen. Arch. Mikrobiol. 2, 352.

LochHead, A. G. \& Herron, D. (1929). Microbiological studies of honey. Canad. Dept. Agr. Bull. No. 116 new series.

Lochuead, A. G. \& Farrell, L. (1931). The types of osmophilic yeasts found in normal honey and their relation to fermentation. Canad. J. Res. 5, 665.

LochHead, A. G. \& McMasters, N. B. (1931). Yeast infection of normal honey and its relation to fermentation. Sci. Agric. 2, 351.

Mrak, E. M. \& Phaff, H. J. (1948). Yeasts. Ann. Rev. Microbiol. p. 61.

Nickerson, W. J. (1943). Zygosaccharomyces acidifaciens: A new acetifying yeast. Mycologia, 35, 66.

Nickerson, W. J. \& Carroll, W. R. (1945). On the metabolism of Zygosaccharomyces. Arch. Biochem. 7, 257.

Nussbaumer T. (1910). Beitrag zur Kenntnis der Honiggärung nebst Notizen über die chemische Zusammensetzung des Honigs. Z. Untersuch. Nahr.-u. Genussm. $20,272$.

Owen, W. L. (1948). The Microbiology of Sugars, Syrups and Molasses. Minneapolis, Minnesota, U.S.A.: Burgess Publishing Co.

Phaff, H. J. \& Mrak, E. M. (1948). Sporulation in yeasts. Part 1. Wallerstein Lab. Commun. 11, 35.

Phaff, H. J. \& Mrak, E. M. (1949). Sporulation in yeasts. Part 2. Wallerstein Lab. Commun. 12, 36.

Sacchetri, M. (1939). Studi su lieviti. Mem. R. Accad. Bologna, 6, 43.

SACCHETt, M. (1932). Richerche sulla fermentazione di un moto d'uva concentrato. Arch. Mikrobiol. 3, 473.

Whalley, H. C. S. DE (1937). A rapid method for the determination of invert in white sugars. Int. Sug. J. 39, 300. 

Journal of General Microbiology, Vol. 5, No. 4

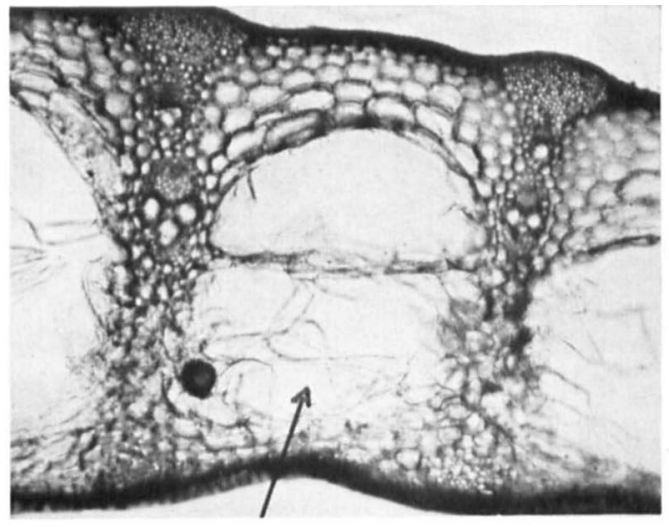

Fig. 1

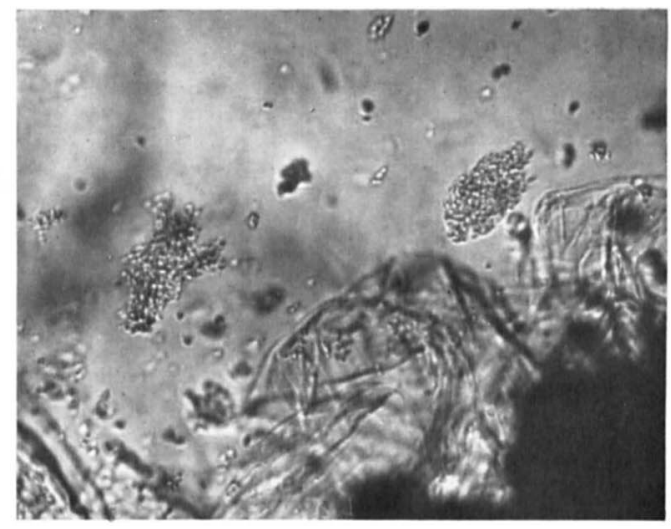

Fig. 2

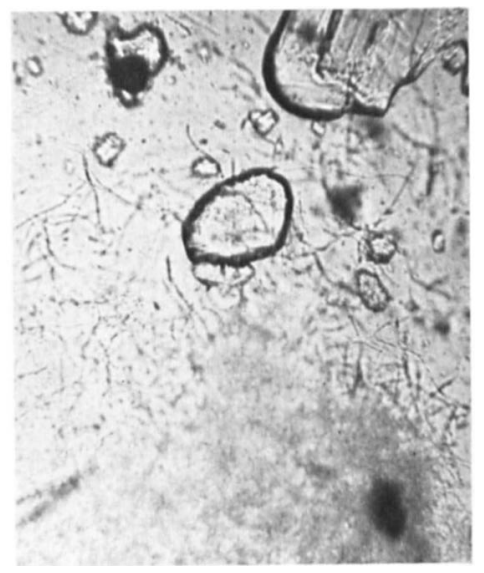

Fig. 3

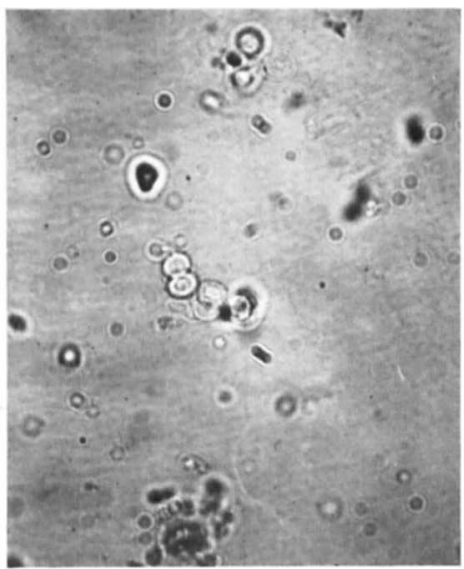

Fig. 4

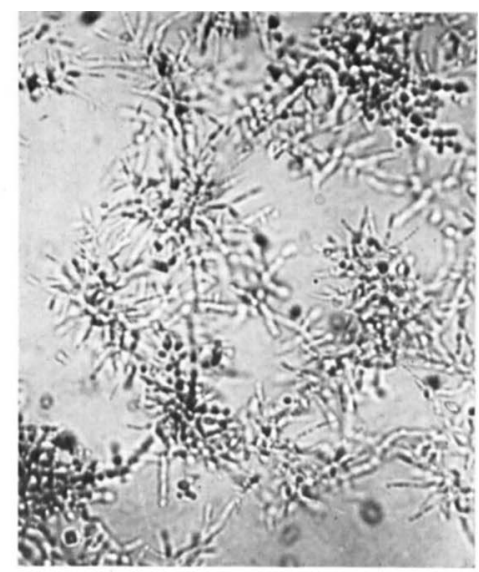

Fig. 5

M. Pamela Scarr-Osmophilic Yeasts in Raw Beet and Cane Sugars and Intermediate Sugar Refining Products. Plate 1 
Whalley, H. C. S. De \& Scarr, M. P. (1947). Micro-organisms in raw and refined sugars and intermediate products. Chem. \& Industr. 351.

Wickerham, L. J. \& Burton, L. F. (1948). Carbon assimilation tests for the classification of yeasts. J. Bact. 56, 363 .

\section{EXPLANATION OF PLATE}

Fig. 1. Transverse section, part of sheathing leaf base of sugar cane with arrow showing where most of the yeasts were found. $\times 37$.

Fig. 2. Yeast growing in the region marked with arrow in Fig. 1; from dissection of fresh cane. $\times 120$.

Fig. 3. Water mount of raw beet sugar showing contamination with hyphae of Aspergillus glaucus. $\times 90$.

Fig. 4. Ascospore formation in 4-weeks' old wort agar streak of Zygosaccharomyces sp. isolated from Peruvian raw cane sugar. About $50 \%$ of the cells have formed asci; there was considerable drying out of the medium. $\times 900$.

Fig. 5. Pseudomycelium formation from the sediment in a wort broth culture of the strain 21 Zygosaccharomyces sp. The formation develops in about 2 weeks. $\times 900$.

(Received 3 October 1950) 